\title{
Та-Nb МИНЕРАЛИЗАЦИЯ В КЕРАМИЧЕСКИХ ПЕГМАТИТАХ СЕВЕРНОГО ПРИЛАДОЖЬЯ: СОСТАВ И УСЛОВИЯ ОБРАЗОВАНИЯ
}

Егоров А.B. ${ }^{1}$, Арзамасцев А.A. ${ }^{1,2}$

${ }^{1}$ Институт наук о Земле СПбГУ, Санкт-Петербург, egorovalex.nw@gmail.com

${ }^{2}$ Институт геологии и геохронологии докембрия РАH, Санкт-Петербург, arzamas@ipgg.ru

В пределах Питкярантского пегматитового поля Северного Приладожья известно несколько месторождений керамических пегматитов, отработка которых в основном завершена. Помимо крупных пегматитовых тел на территории поля насчитывается более 400 мелких пегматитовых жил. Образование пегматитового поля связывают с коллизионным этапом развития региона, в течение которого произошло внедрение синорогенных гранитных комплексов: Маткаселькского, Импиниемского (1871 \pm 12 млн. лет) [3], Тервуского (1858.8 \pm 2.5 млн. лет) [2]. Зачастую выявление связи гранитов с пегматитами в пределах Питкярантского поля весьма затруднительно, так как пространственная связь данных образований хорошо прослеживается только в пределах гранитных комплексов. Вмещающими породами для пегматитов является архейские гранито-гнейсы, слагающие купольные структуры, а также супракрустальные раннепротерозойские породы питкярантской свиты (рис. 1). Размещение пегматитовых жил контролируется системой тектонических нарушений северо-западного и субмеридионального простирания, которые были заложены в период свекофеннской складчатости. Обновление тектонической активности в последующий постколлизионный период привело к изменению существующих пегматитовых тел, которое проявилось в милонитизации и интенсивных метасоматических преобразованиях. Постколлизионные изменения связывают с плагиомикроклиновыми и микроклин-плагиоклазовыми мигматит-гранитами [4].

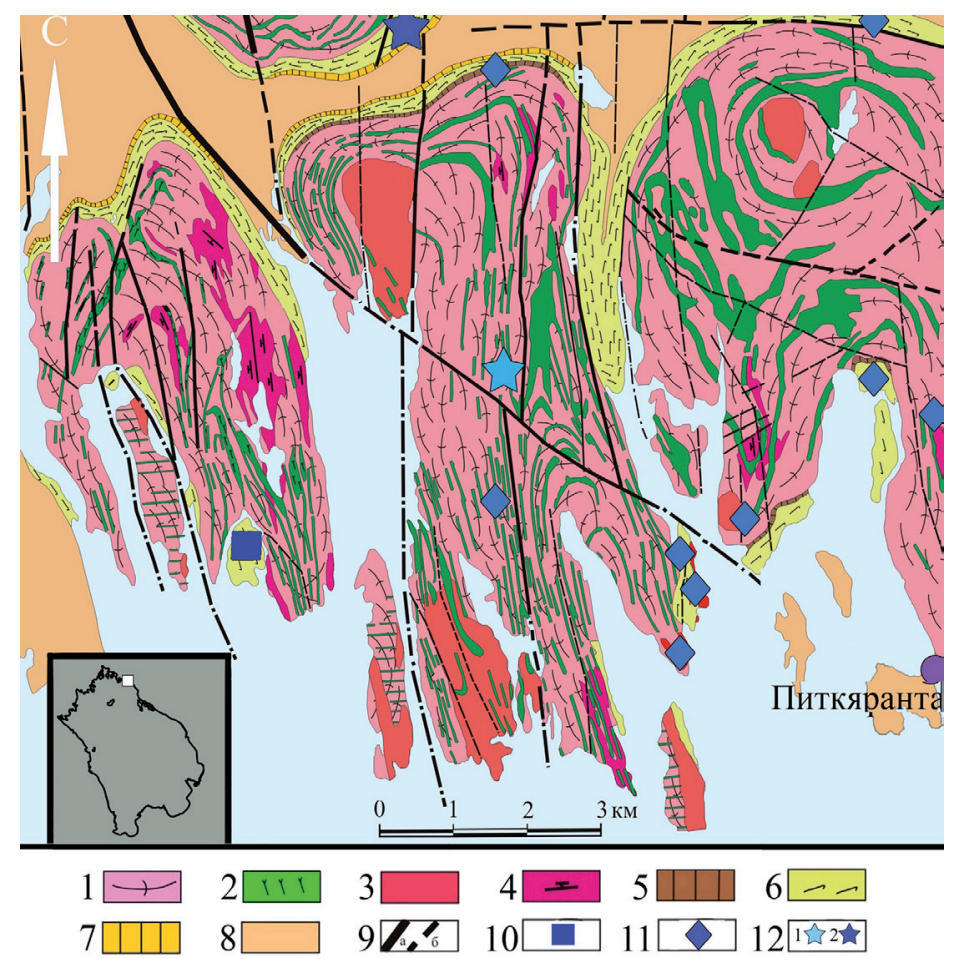

Рис. 1. Схема геологического строения района работ [9].

1 - гранито-гнейсы; 2 - амфиболиты; 3 - плагиомикроклиновые граниты; 4 - микроклин-плагиоклазовые граниты; 5 - нижний карбонатный горизонт питкярантской свиты; 6 - амфиболиты питкярантской свиты; 7 - верхний карбонатный горизонт питкярантской свиты; 8 - кварцевые песчаники, кварц-биотитовые сланцы ладожской серии; 9 - разломы: а) достоверные, б) предполагаемые; 10 - Импиниемский диорит-гранодиоритовый комплекс; 11 - месторождения керамических пегматитов Питкярантского поля; 12 - проявления Та-Nb минерализации в пегматитах: 1) участок работ, 2) месторождение Линнаваара. Врезка - местоположение района, контур - Ладожское озеро. 
По данным К.И. Степанова [3] с постколлизионными метасоматическими изменениями пегматитов месторождения Линнаваара связана редкометальная Ta-Nb минерализация, приуроченная к вторичным прожилкам мусковит-кварц-альбитового состава.

В ходе полевых работ нами исследовано пегматитовое тело, локализованное в пределах ядра Мурсульского гранито-гнейсового купола. Вскрытая шурфом пегматитовая жила залегает в архейских (возраст $2659 \pm 15$ млн. лет) [1] гранито-гнейсах (рис. 2), которые смяты в линейные изоклинальные складки с крутопадающими крыльями. Гранито-гнейсы простираются субмеридионо и характеризуются вертикальным падением. Пегматитовая жила представляет собой дискордантное изогнутое линзообразное тело протяженностью 35 м и видимой мощностью от 1 до 10 м. Глубина шурфа в центральной части жилы - 3 м. Южная часть жилы сильно задернована, предполагаемая граница проведена по данным радиометрической съемки.

При изучении тела было выявлено характерное зональное строение. На границе с вмещающими гранито-гнейсами присутствует краевая зона, представленная срастаниями крупнокристаллического полевого шпата. Промежуточная зона сложена прорастающими совместно полевым шпатом и кварцем. В центральной части тела развиты блоки микроклина, которые вскрыты шурфом.

В пределах южного борта шурфа наблюдаются

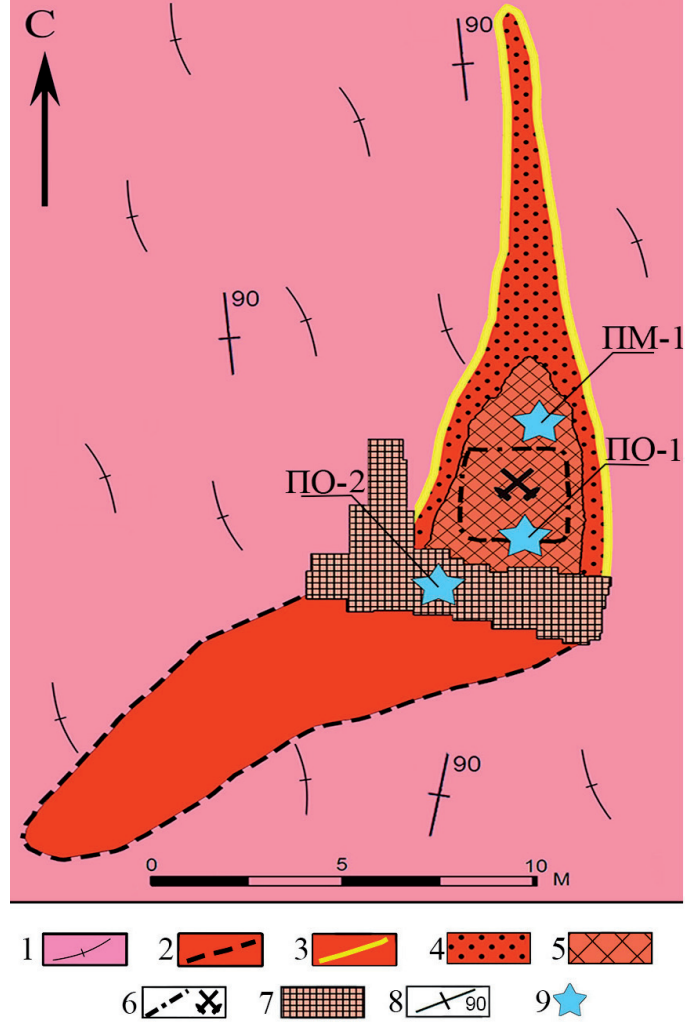

Рис. 2. Геологический план участка работ. 1 - гранито-гнейсы; 2 - предполагаемая граница жилы; 3 - краевая зона; 4 - промежуточная зона; 5 - центральная зона; 6 - шурф; 7 - отвалы шурфа; 8 - элементы залегания; 9 - места отбора проб: ПМ-1, ПО-1, ПО-2. небольшие (3-5 см) мусковит-кварц-альбитовые прожилки, секущие блоковый микроклин. В отвалах шурфа обнаружены образцы, содержащие срастания крупных (до 10 см) кристаллов мусковита, кварца и олигоклаза, а также биотита, кварца и микроклина. Также в отвалах наблюдаются крупные (до 25 см) осколки молочно-белого и серого кварца на основании которых можно сделать вывод о присутствовавшем в жиле кварцевом ядре.

Для исследований отобраны три пробы (> 8 кг каждая): 1) ПМ-1 - проба из центральной зоны крупнокристаллического микроклина; 2) ПО-1 - проба из мусковит-кварц-альбитовых прожилков из южного борта карьера; 3) ПО-2 - проба, состоящая из образцов мусковит-кварц-олигоклазового срастания, из отвалов. Помимо крупных проб для каждой из зон отбирались штуфные образцы.

Породообразующими минералами пегматитовой жилы являются полевые шпаты, мусковит, биотит и кварц. Также присутствуют многочисленные скопления мелких (до 0.5 мм) кристаллов спессартина и гнездовые выделения магнетита (до 1 см). В подчиненном количестве наблюдаются второстепенные минералы: пирит, халькопирит, апатит, циркон, рутил, ильменит, ильменорутил, колумбит, монацит, ксенотим, бетафит, ураноторит.

В пробе ПО-1, отобранной из прожилков мусковит-кварц-альбитового состава, была установлена $\mathrm{Ta}-\mathrm{Nb}$ минерализация, которая также присутствует в пробе ПО-2, но характеризуется меньшим содержанием. Наблюдается две формы выделения Ta-Nb-содержащих минералов: твердые растворы изоморфного ряда ферроколумбит $\mathrm{Fe}^{2+} \mathrm{Nb}_{2} \mathrm{O}_{6}-$ ферротанталит $\mathrm{Fe}^{2+} \mathrm{Ta}_{2} \mathrm{O}_{6}$ в составе рутила (рис. 3 а) и редкие радиоактивные минералы, схожие по химическому составу с лиандратитом $\mathrm{U}(\mathrm{Nb}, \mathrm{Ta})_{2} \mathrm{O}_{8}$ и ишикаваитом $(\mathrm{U}, \mathrm{Fe}) \mathrm{NbO}_{4}$. Включения в рутиле представляют собой относительно мелкие $(5-80 \mu \mathrm{m})$ обособления неправильной формы. Размер зерен рутила варьирует в пределах 0.1-1.2 мм, при высокой концентрации включений наблюдается мозаичная структура. По химическому составу включения соответствуют ферроколумбиту с изоморфными примесями $\mathrm{Mn}$ и $\mathrm{Sc}$.

Выделения $\mathrm{Ta}-\mathrm{Nb}$ минералов в виде включений в рутиле встречаются довольно часто. 


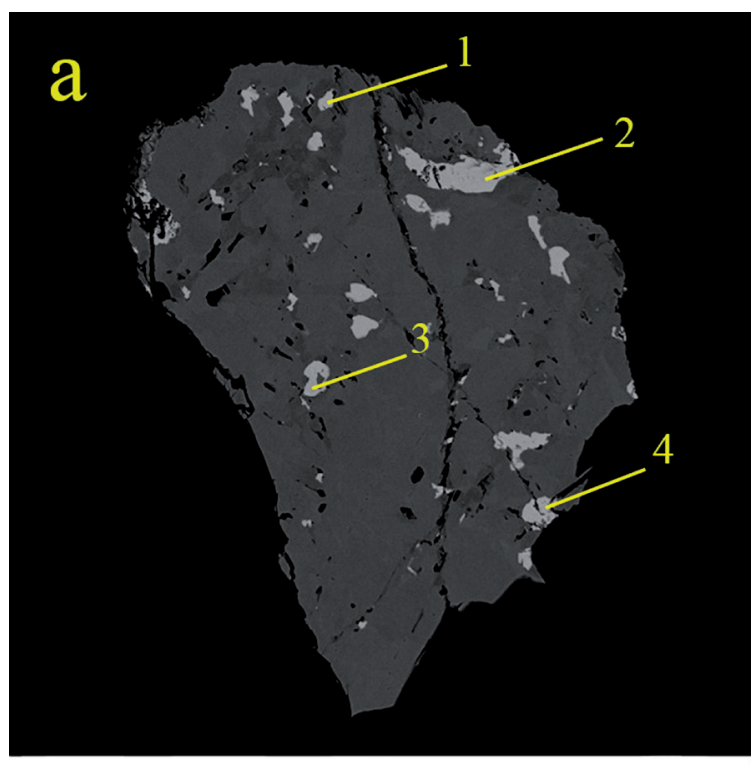

$400 \mu \mathrm{m}$

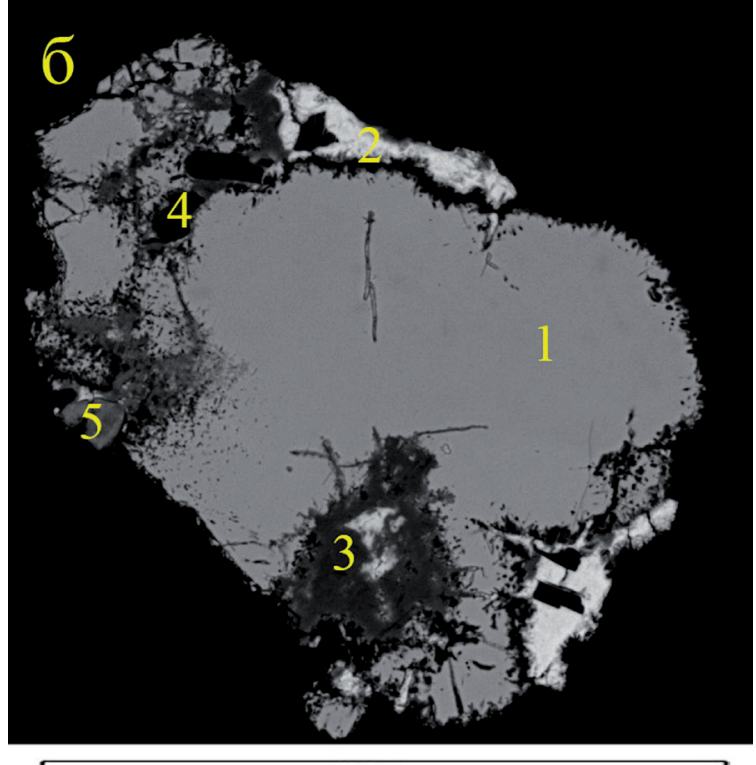

$150 \mu \mathrm{m}$

Рис. 3. Формы выделения Ta-Nb минералов, микрофотографии в режиме отраженных электронов (электронный микроскоп Hitachi S-4300N).

a - включения ферроколумбита (светлые) в рутиле, состав включений приведен в таблице 1 ;

б - срастания ферроколумбита и лиандратита: 1 - ферроколумбит, 2 - лиандратит, 3 - магнетит, 4 - включения микроклина, 5 - включение циркона.

Реже тантало-ниобаты наблюдаются в виде сложных срастаний с многочисленными различными по составу включениями (рис. 3 б). Данные срастания не превышают размера $200 \mu \mathrm{m}$ и, возможно, являются осколками более крупных минеральных индивидов. В качестве основных минералов в срастаниях выступают ферроколумбит и лиандратит, в составе которых наблюдаются включения микроклина. Размер включений микроклина не превышает $10 \mu \mathrm{m}$, каплевидная форма выделения свидетельствует о том, что осколки были захвачены в процессе роста ферроколумбита и лиандрита и переработаны. Циркон присутствует в виде единичного каплевидного включения в ферроколумбите, что, опять же, говорит о его более раннем образовании по отношении к вмещающему минералу. По периметру включений в ферроколумбите присутствуют зоны развития магненита.

Таблица 1. Химический состав включений ферроколумбита в рутиле, мас. \%.

\begin{tabular}{|c|l|l|l|l|l|l|}
\hline $\begin{array}{c}\text { Номер } \\
\text { включения }\end{array}$ & $\mathrm{Sc}_{2} \mathrm{O}_{3}$ & \multicolumn{1}{|c|}{$\mathrm{TiO}_{2}$} & $\mathrm{MnO}_{2}$ & \multicolumn{1}{|c|}{$\mathrm{FeO}$} & $\mathrm{Nb}_{2} \mathrm{O}_{5}$ & $\mathrm{Ta}_{2} \mathrm{O}_{5}$ \\
\hline 1 & 3.30 & 8.45 & 2.32 & 14.68 & 65.32 & 5.92 \\
\hline 2 & 2.76 & 5.81 & 7.66 & 13.12 & 66.29 & 4.36 \\
\hline 3 & 3.14 & 6.45 & 8.97 & 8.61 & 66.42 & 6.41 \\
\hline 4 & 2.21 & 7.24 & 2.74 & 18.18 & 66.01 & 3.61 \\
\hline
\end{tabular}

По результатам рентгенофлуоресцентного анализа и масс-спектрометрии (ICP-MS) были определены содержания петрогенных, REE и малых элементов. Для установления возможного источника пегматитового расплава полученные составы проб исследуемого пегматитового тела сопоставлялись с составами кислых интрузий эпохи свекофеннской складчатости: предколлизионным Куркиекским и синколлизионным Тервуским плутонами [2] (рис. 4).

График распределения редкоземельных и малых элементов в пробах из пегматитовой жилы характеризуется явно выраженными отрицательными аномалиями для $\mathrm{Ba}, \mathrm{Sr}, \mathrm{Eu}$ и Ti. При этом присутствуют аномально высокие содержания радиоактивных элементов (U,Th). Повышенное содержание характерно также для Rb и Nb. Содержание HREE несущественно преобладает над LREE, отношение $(\mathrm{La} / \mathrm{Yb})_{n}$ для проб из пегматитовой жилы установлено в пределах единицы. 


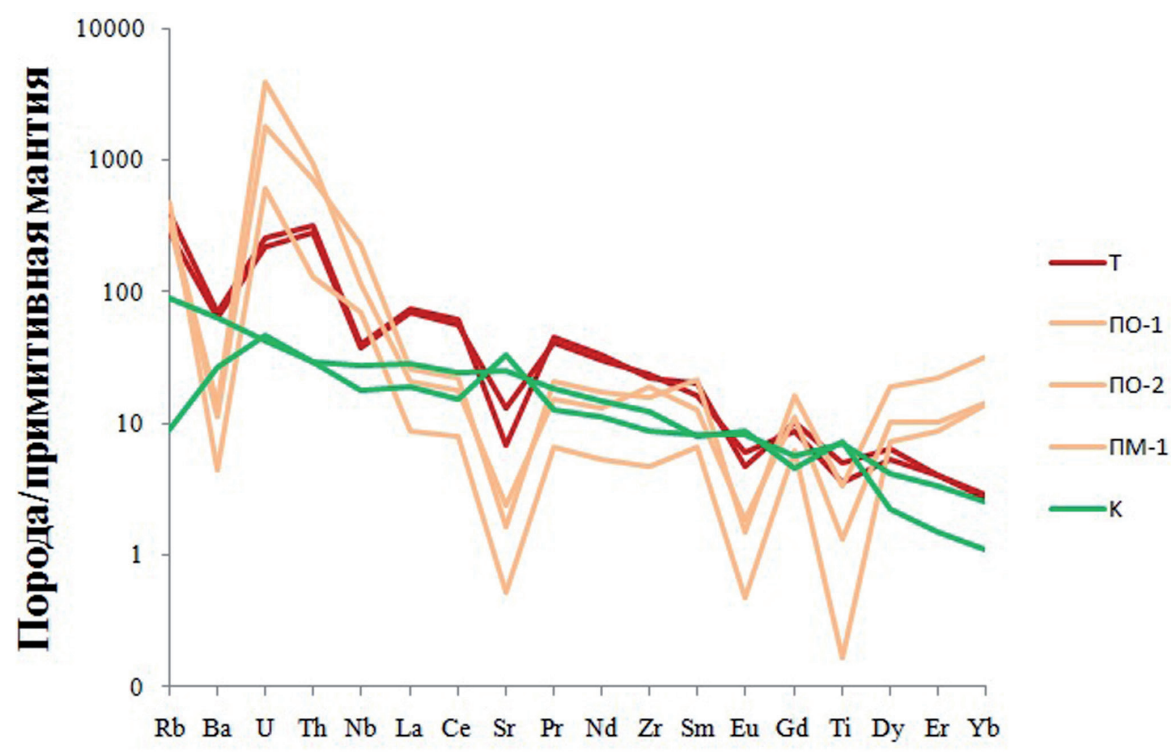

Рис. 4. Распределение редкоземельных и малых элементов в исследуемой пегматитовой жиле (ПО-1, ПО-2, ПМ-1) и кислых свекофеннских плутонах Тервус (Т) и Куркиеки (К).

Нормирование на состав примитивной мантии [5].

Сопоставив тренд распределения редкоземельных и малых элементов в породах Куркиекско-

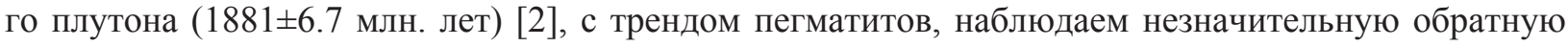
корреляцию - слабые $\mathrm{Sr}, \mathrm{Eu}, \mathrm{Ti}$ положительные аномалии.

Явно выраженная корреляция в распределении REE и малых элементов наблюдается между пробами из пегматитовой жилы и гранитами Тервуского плутона (1858.8 2.5 млн.лет) [2]. Для гранитов Тервуского плутона, как и для исследуемых пегматитов характерны положительные аномалии $\mathrm{Rb}, \mathrm{U}$, Th и отрицательные аномалии для $\mathrm{Ba}, \mathrm{Sr}, \mathrm{Eu}, \mathrm{Ti}$. В распределении REE наблюдаются различия: повышенное содержание LREE при более низких значениях HREE, отношение (La/Yb) ${ }_{n}$ равно 70. Граниты Тервуского плутона являются синколлизионными, их образование связывают с селективным плавлением и мигматизацией вмещающих гранито-гнейсовых толщ.

Учитывая характер распределения редкоземельных и малых элементов, можно установить связь между исследуемой пегматитовой жилой и гранитами Тервуского типа. По видимому, пегматитовая жила была сформирована на завершающей стадии кристаллизации расплава синколизионных гранитов. Однако, пространственной связи пегматитов и гранитов в пределах участка работ не выявлено.

Повышенное содержание радиоактивных элементов в пегматите объясняется пространственной близостью U-Th рудопроявления Пюттюмяки, которое приурочено к посторогенным мигматит-

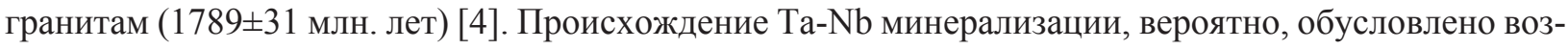
действием флюидонасыщенных гидротермальных растворов мигматит-гранитов. В пользу связи $\mathrm{Ta}-\mathrm{Nb}$ минерализации с мигматит-гранитами рудопроявления Пюттюмяки свидетельствует присутствие U-содержащих тантало-ниобатов: лиадратита и ишикаваита.

\section{Литература}

1. Мыскова Т.А., Милькевич Р.И., Львов П.А. U-Pb геохронология (SRIMP-II) цирконов из метаосадков ладожской серии (Северное Приладожье, Балтийский щит). Т 20. // Стратиграфия. Геологическая корреляция. 2012. № 2. С. 1-13.

2. Седова И.С., Саморукова Л.М. Глебовицкий В.А., Крылов Д.П., Геохимия гранитоидов Свекофеннского тектоно-метаморфического цикла Северного Приладожья // Петрология. 2004. Т. 12. № 4. С. 394-414.

3. Степанов К.И., Санин Д.М., Санина Г.Н. Государственная геологическая карта масштаба 1:200 000 (второе издание). Листы Р-35-XXIV, Р-36-XIX // Объяснительная записка. Гл.ред. Ю.Б. Богданов, отв. ред. В.Г. Легкова. СПб: Изд-во СПб картфабрики ВСЕГЕИ. 2004. С. 74-85.

4. Шурилов А.В., Полеховский Ю.С., Тарасова И.П. Радиоактивная минерализация Импилахтинского полигона геологического факультета СПбГУ (Северное Приладожье): уч. Пособие . СПб: С.-Петерб. ун-т, 2013. C. 9-23.

5. McDonough W.F., Sun S.S., The composition of the Earth. Chem. Geol. 1995. V. 120. P. 223-253. 